\title{
Analysis of Macrophages and Peptidergic Fibers in the Skin of Patients With Painful Diabetic Polyneuropathy
}

Sandra Sif Gylfadottir, MD, PhD, Mustapha Itani, MD, Alexander Gramm Kristensen, MD, PhD, Hatice Tankisi, MD, PhD, Troels Staehelin Jensen, MD, PhD, Søren H. Sindrup, MD, PhD,

David L.H. Bennett, MD, Jens Randel Nyengaard, MD, PhD, Nanna Brix Finnerup, MD, and Pall Karlsson, PhD

Neurol Neuroimmunol Neuroinflamm 2022;9:e1111. doi:10.1212/NXI.0000000000001111

\section{Abstract}

\section{Background and Objectives}

The mechanisms of pain in patients with diabetic polyneuropathy are unknown. Studies have suggested a role of inflammation and increased neuropeptides peripherally in pain generation. This study examined the possible skin markers of painful diabetic polyneuropathy (P-DPN): macrophages, substance P (SP), and calcitonin gene-related peptide (CGRP).

\section{Methods}

The participants were included from a large Danish cross-sectional clinical study of type 2 diabetes. We diagnosed definite diabetic polyneuropathy using the Toronto criteria and used the Neuropathic Pain Special Interest Group classification for defining P-DPN. We included 60 skin biopsies from patients with diabetic polyneuropathy-30 with P-DPN and 30 with nonpainful diabetic polyneuropathy (NP-DPN) - and 30 biopsies from healthy controls of similar age and sex. The biopsies were stained using PGP 9.5, IbA1, and SP and CGRP primary markers.

\section{Results}

There was increased macrophage density in patients with P-DPN (8.0\%) compared with that in patients with NP-DPN $(5.1 \%, p<0.001)$, and there was increased macrophage density in patients with NP-DPN $(5.1 \%)$ compared with that in healthy controls $(3.1 \%, p<0.001)$. When controlling for neuropathy severity, body mass index, age, and sex, there was still a difference in macrophage density between patients with P-DPN and patients with NP-DPN. Patients with P-DPN had higher median nerve fiber length density $\left(274.5\right.$ and $155 \mathrm{~mm}^{-2}$ for SP and CGRP, respectively) compared with patients with NP-DPN (176 and $121 \mathrm{~mm}^{-2}$ for SP and CGRP, respectively, $p=0.009$ and 0.04 ) and healthy controls (185.5 and $121.5 \mathrm{~mm}^{-2}$ for SP and CGRP, respectively), whereas there was no difference between patients with NP-DPN and controls without diabetes ( $p=0.64$ and 0.49 , respectively). The difference between P-DPN and NP-DPN for SP and CGRP was significant only in female patients, although a trend was seen in male patients.

\section{Discussion}

The findings point to a possible involvement of the innate immune system in the pathogenesis of neuropathic pain in patients with DPN, although markers of activated macrophages were not measured in this study.

\author{
Correspondence \\ Dr. Karlsson \\ pall@clin.au.dk
}




\section{Glossary}

BMI = body mass index; CGRP = calcitonin gene-related peptide; $\mathbf{D P N}=$ diabetic polyneuropathy; IENFD = intraepidermal nerve fiber density; IQR = interquartile range; LC = Langerhans cells; NCS = nerve conduction studies; NFLD = nerve fiber length density; NP-DPN = nonpainful diabetic polyneuropathy; NPSI = Neuropathic Pain Symptom Inventory; NRS = numeric rating scale; $\mathbf{P}-\mathbf{D P N}=$ painful diabetic polyneuropathy; $\mathbf{S P}=$ substance $\mathbf{P}$; TCNS = Toronto Clinical Neuropathy Score.

Diabetic polyneuropathy (DPN) is a common complication of diabetes, with a lifetime prevalence of up to $50 \% .{ }^{1}$ The most common type of DPN is an axonal, length-dependent, sensorimotor peripheral neuropathy, characterized by the presence of neuropathic pain and/or sensory loss and signs of nerve damage in a glove-like and stocking-like distribution. Painful DPN (P-DPN) is reported in $25 \%-40 \%$ of patients with diabetes and is associated with reduced quality of life..$^{2-5}$ Our ability to treat the pain in DPN is inadequate mainly because of lack of understanding of the mechanisms driving the neuropathy and the pain.

In DPN, both small (unmyelinated or thin myelinated nerve fibers) and large myelinated fibers are affected. ${ }^{6,7}$ A hallmark of DPN with small fiber involvement is a decrease of intraepidermal nerve fiber density (IENFD), as detected by punch skin biopsy and immunostaining using the panneuronal marker PGP 9.5. ${ }^{8}$ Although there is evidence that the severity of DPN is predictive of neuropathic pain, there is a poor correlation between IENFD and the presence and intensity of neuropathic pain. ${ }^{9}$ Hence, a decrease of IENFD is not in itself sufficient to explain the presence and development of neuropathic pain. By focusing on cellular elements and signaling molecules known to be involved in the generation of neuropathic pain, we hope to better understand the relationship between morphology and function..$^{10,11}$

Immune cells may play an important role in neuropathic pain, both peripherally and centrally. ${ }^{12-14}$ Neurons and immune cells, including dendritic cells, interact functionally and can even form the so-called neuroimmune cell units, as highlighted in recent reviews. ${ }^{15-17}$ Dendritic cells have been shown to play a role in antigen presentation, secrete proinflammatory cytokines, and may sensitize the nociceptors in the skin. ${ }^{13}$ In addition, pilot findings from a recent study found increased density of skin macrophages in patients with P-DPN, ${ }^{18}$ suggesting that macrophages may contribute to neuropathic pain in DPN.

Other potential pathophysiologic mechanisms underlying neuropathic pain include small nerve fibers that express the neuropeptide substance $\mathrm{P}(\mathrm{SP})$ and calcitonin gene-related peptide (CGRP). ${ }^{19,20}$ Recently, we demonstrated an increased density of peptidergic fibers containing SP and CGRP in a group of diabetic patients with a painful small fiber neuropathy compared with diabetic patients with small fiber neuropathy but without pain. ${ }^{21}$ Indeed, the activation of nociceptors causes a release of these neuropeptides. ${ }^{19,20}$ Taken together, these studies raise the possibility that both macrophages in the skin and increased density of SPexpressing and CGRP-expressing nerve fibers might separate P-DPN from the nonpainful diabetic polyneuropathy (NP-DPN). In this study, we compared macrophage density in the skin between patients with P-DPN and patients with NP-DPN and the density of SP-positive and CGRP-positive nerve fibers.

\section{Methods}

\section{Standard Protocol Approvals, Registrations, and Patient Consents}

This study was approved by the Regional Research Ethics Committee of Central Denmark Region (\#1-10-72-130-16), and all study participants gave written, informed consent according to the Declaration of Helsinki.

\section{Study Participants and the Definition and Assessment of DPN and P-DPN}

The participants included in this study were part of a larger cross-sectional study of 389 recently diagnosed patients with type 2 diabetes from the Danish Center for Strategic Research in Type 2 diabetes (DD2) cohort and 97 healthy controls without diabetes, confirmed by normal values of $\mathrm{HbAlc}$, and of similar age and sex. The original study was conducted in 2016-2018 in Aarhus and Odense, Denmark. ${ }^{22}$ In this study, we randomly selected 60 patients from the 389 patients included in the clinical study, 30 with NP-DPN, 30 patients with P-DPN, and 30 controls without diabetes of similar age and sex (eFigure 1, links.lww.com/NXI/A650). The criteria for the selection were as follows: skin biopsy in association for meeting criteria for inclusion as confirmed DPN or control participant. Of the total sample of 486 participants, $13 \%$ did not have skin biopsies taken because of a medical contraindication to skin biopsy or participant declining skin biopsy.

More detailed description of inclusion and exclusion criteria is described elsewhere. ${ }^{5,22}$ In brief, all study participants including controls underwent detailed neurologic examination, including history taking and sensory mapping of lower extremities, nerve conduction studies (NCSs), and quantification of IENFD from skin biopsy to confirm the diagnosis of DPN and P-DPN. The Toronto Clinical Neuropathy Score (TCNS) was performed to grade the severity of the DPN. 


\section{Clinical Diagnosis of DPN and Pain}

The diagnosis was made in accordance with the Toronto Diabetic Neuropathy Expert Group criteria ${ }^{23}$ for DPN (at least 1 of sensory symptoms, signs, or reduced ankle reflexes in combination with abnormal NCS or IENFD) and the updated definition of neuropathic pain provided by the Neuropathic Pain Special Interest Group ${ }^{24}$ for P-DPN (diabetes diagnosis, pain in both feet/legs, and sensory signs in the feet/legs in combination with abnormal IENFD or NCS after excluding other causes of pain). Patients with pain rated their neuropathic pain in the past 24 hours on a numeric rating scale (NRS) from 0 to 10 , with 0 indicating no pain and 10 being the worst pain imaginable. Patients also filled in the Neuropathic Pain Symptom Inventory (NPSI), a questionnaire designed to evaluate the characteristics and intensity of neuropathic pain symptoms. ${ }^{25}$ As a surrogate for DPN severity, we used the TCNS, which is a diagnostic tool for DPN including questions and clinical examination of lower extremities. Using the total score, the severity of DPN can be assessed. ${ }^{26,27}$

The NCS consisted of examination of sural nerve bilaterally and the median, peroneal, and tibial nerves unilaterally. Polyneuropathy was defined as $\geq 2$ nerves with $\geq 1$ abnormal parameter with at least 1 sural nerve being abnormal compared with a laboratory control sample from a national database (which includes our study site). ${ }^{28-30}$ In cases in which there was clinical or electrophysiologic suspicion of mononeuropathies or lumbosacral plexopathy, additional nerves were examined.

\section{Skin Biopsies}

Three-millimeter punch skin biopsies (Miltex, York, PA) were taken under sterile conditions after intradermal injection of $1 \%$ lidocaine $10 \mathrm{~cm}$ proximal to the lateral malleolus, as previously in accordance with published guidelines. ${ }^{8}$

In brief, the specimens were fixed in Zamboni fixative overnight (not exceeding 24 hours), cryoprotected in $20 \%$ sucrose $0.1 \mathrm{M}$ phosphate buffer overnight, snap frozen, and stored at $-20^{\circ} \mathrm{C}$ until further processing. A total of 16 (4 for each primary antibody) nonconsecutive $50-\mu \mathrm{m}$ thick sections were cut using a freezing microtome and processed with PGP 9.5 (1:2,000, Zytomed, Berlin, Germany) for IENFD analysis and indirect immunofluorescence technique using the following primary markers and appropriate secondary antibodies on free-floating sections: SP (1:1,000; Immunostar, Hudson, WI), CGRP (Immunostar, Hudson, WI), and IbA1 (1:500; Wako Chemicals, Richmond, VA). This ensured that at least 3 sections were available for counting for each staining because occasionally, 1 section is lost during the staining process. The sections were stained free-floating in 96-well filter plates, which allows the sections to be exposed to the solutions from both sides. On sectioning, the sections were washed and incubated in a blocking solution ( $5 \%$ normal serum, $1 \%$ triton $\mathrm{X}-100$, and $1 \%$ powdered milk) for 4 hours. The sections were incubated with primary antibodies overnight and after a washing step with appropriate secondary antibodies overnight. Finally, the sections were mounted on slides and coverslipped.

IENFD (expressed as fibers/linear mm) was determined by counting PGP 9.5-immunoreactive nerve fibers crossing the epidermis from the dermis under an $\mathrm{x} 40$ objective and dividing this number with the length of the sections. IENFD was considered abnormal if it was below the fifth centile for agematched and sex-matched healthy controls. ${ }^{8}$

SP and CGRP innervations were assessed using the stereological 3D sampling technique global spatial sampling ${ }^{31}$ and are expressed as nerve fiber length density (NFLD). The stereological estimation of NFLD ensures unbiased and accurate estimation and is described in detail elsewhere. ${ }^{31,32}$ In brief, when using global spatial sampling, a stereological software (NewCAST, Visiopharm, Hoersholm, Denmark) superimposes a virtual 3D counting box consisting of isotropic planes as a live layer when assessing the NFLD, thus ensuring that all fibers have the same chance of being counted and eliminating counting bias. ${ }^{33}$ This way, we were able to get an accurate estimation of the nerve fiber length per tissue volume (including the tissue thickness) under live microscopy.

Macrophage (IbA1) density was quantified using ImageJ (NIH and LOCI, WI), where a threshold RBG intensity was set before the analysis to eliminate unspecific background staining intensity, and the area of the region of interest that exhibited fluorescence above the threshold was reported as a percentage value of the entire region of interest, which was from the epidermal-dermal junction and $500 \mu \mathrm{m}$ down. ${ }^{18,33}$ The IbA1 antibody labels both macrophages and Langerhans cells (LCs). ${ }^{34}$ LC cell labelings are unlikely to have influenced the results because these cells are mainly present in the suprabasal epidermal layers, ${ }^{35}$ which was the focus area in this study. The staining was stable and reliable for all antibodies, and in general, there was a low intravariation between the sections stained. All counting was performed in a blinded fashion.

\section{Statistical Analysis}

We used the STATA, version 14 (StataCorp LLC, TX), and R Core Team (Vienna, Austria, 2019) ${ }^{36}$ for data analysis. Normality was checked using histograms and Shapiro-Wilk tests. Data were presented accordingly as medians with interquartile range (IQR) or means with SD. Categorical data were presented as numbers with percentages. We compared groups with the Kruskal-Wallis test, analysis of variance, or Fisher exact test between all 3 DPN groups and with the MannWhitney $U$ test, student $t$ test, or Fisher exact test for paired comparisons. We used Spearman rank correlation to measure the strength and the direction of the association between clinical signs and symptoms of DPN and macrophage density or neuropeptide density. A $p$ value of $<0.05$ was considered statistically significant. We used a logistic regression model to estimate the association between macrophage density and 
P-DPN vs NP-DPN, adjusting for body mass index (BMI), neuropathy severity, as measured by the total TCNS, age, and sex.

\section{Data Availability}

Deidentified data are available from the corresponding author on request pending signed agreements from Aarhus University.

\section{Results}

\section{Clinical Characteristics}

There was no difference in age between the 3 groups of participants or diabetes duration between the 2 groups of patients (Table 1). There were more men in the group of patients with NP-DPN, and patients with P-DPN had more severe DPN than patients without pain, measured by the TCNS (median 9.0 [IQR 7.0; 12.0] vs $6.5[4.0 ; 8.0], p<$ 0.001 ). Patients with P-DPN had lower IENFD count 0.8
$(0.3 ; 2.7)$ compared with patients with NP-DPN or 2.3 $(1.2 ; 3.9)$ fibers $/ \mathrm{mm}, p=0.02$. The median pain rating on the NRS in the past 24 hours was $5.0(4.0 ; 8.0)$ in patients with P-DPN with female patients reporting higher pain intensity compared with male patients, $(6.0[5.0 ; 8.0]$ vs $4.0[3.0 ; 7.0]$, $p=0.03)$, data not shown.

\section{Macrophages and Neuropeptides}

There was a gradient of increasing macrophage density in the skin from controls to patients with NP-DPN and to patients with P-DPN (3.1\%, 5.1\%, and 8.0\%, respectively; $p<0.001$ ) (Figure 1). Patients with P-DPN had higher macrophage infiltration compared with patients with NP-DPN $(p=0.001)$. After controlling for total TCNS, BMI, age, and sex, the difference between P-DPN and NP-DPN remained significant (odds ratio for macrophage infiltration in P-DPN vs NP-DPN $1.46, p=0.014$ ), and patients with P-DPN had higher total TCNS than patients with NP-DPN (total TCNS odds ratio for P-DPN vs NP-DPN 1.31, $p=0.008)$.

Table 1 Patient Characteristics and Percentage of Macrophage Density and Neuropeptide-Positive Nerve Fibers in the 3 Groups

\begin{tabular}{|c|c|c|c|c|}
\hline & $\begin{array}{l}\text { Controls without } \\
\text { diabetes, } n=30\end{array}$ & $\begin{array}{l}\text { Patients with } \\
\text { NP-DPN, } n=30\end{array}$ & $\begin{array}{l}\text { Patients with } \\
\text { P-DPN, } n=30\end{array}$ & $p$ Value \\
\hline \multicolumn{5}{|l|}{ Patient characteristics } \\
\hline Sex, female & $19(63.3)$ & $8(26.7)^{a}$ & $15(50.0)$ & 0.014 \\
\hline Age, y (mean, \pm SD) & $60.7( \pm 8.8)$ & $64.1( \pm 9.6)$ & $64.2( \pm 10.9)$ & 0.30 \\
\hline $\mathrm{BMI}, \mathrm{kg} / \mathrm{m}^{2}$ & $26.7(25.0 ; 30.0)$ & $32.8(29.4 ; 36.8)^{a}$ & $34.6(31.5 ; 40.0)$ & $<0.001$ \\
\hline Ever smoking (yes) & $17(56.7)$ & $20(66.7)$ & $16(55.2)$ & 0.64 \\
\hline Duration of diabetes, $y$ & - & $6.2(3.8 ; 7.7)$ & $5.9(4.7 ; 8.1)$ & 0.80 \\
\hline Hba1c & $36.0(35.0 ; 38.0)$ & $49.5(45.0 ; 55.0)^{\mathrm{a}}$ & $52.0(47.0 ; 62.0)$ & $<0.001$ \\
\hline Treatment for hypertension (yes) & $3(10.3)$ & $25(83.3)^{a}$ & $23(76.7)$ & $<0.001$ \\
\hline Pain intensity, 24 h, NRS (0-10) & - & - & $5.0(4.0 ; 8.0)$ & - \\
\hline Pain duration $>1$ y & - & - & $26(86.7)$ & - \\
\hline TCNS (0-19) & $1.5(0.0 ; 2.0)$ & $6.5(4.0 ; 8.0)^{\mathrm{a}}$ & $9.0(7.0 ; 12.0)^{b}$ & $<0.001$ \\
\hline Abnormal ENG & $0(0)$ & $17(58.6)^{\mathrm{a}}$ & $19(63.3)$ & $<0.001$ \\
\hline \multicolumn{5}{|l|}{ Skin biopsy variables } \\
\hline IENFD (fibers/mm) & $7.1(5.0 ; 9.2)$ & $2.3(1.2 ; 3.9)^{\mathrm{a}}$ & $0.8(0.3 ; 2.7)^{\mathrm{b}}$ & $<0.001$ \\
\hline Abnormal IENFD, \% & $1(3.3)$ & $23(76.7)^{a}$ & $26(86.7)$ & $<0.001$ \\
\hline Macrophage infiltration, \% & $3.1(2.5 ; 4.3)$ & $5.1(3.7 ; 6.2)^{a}$ & $8.0(5.0 ; 9.3)^{b}$ & $<0.001$ \\
\hline CGRP NFLD, $\mathrm{mm}^{-2}$ & $121.5(79 ; 182)$ & $121(58 ; 147)$ & $155(99 ; 202)^{\mathrm{b}}$ & 0.12 \\
\hline Substance P NFLD, $\mathrm{mm}^{-2}$ & $185.5(98 ; 307)$ & $176(86 ; 260)$ & $274.5(162 ; 381)^{b}$ & 0.032 \\
\hline \multicolumn{5}{|c|}{$\begin{array}{l}\text { Abbreviations: } \mathrm{BMI}=\text { body mass index; CGRP = calcitonin gene-related peptide; ENG = electroneurografi; IENFD = intraepidermal nerve fiber density; } N F L D= \\
\text { nerve fiber length density; NP=DPN = nonpainful diabetic polyneuropathy; NRS = numeric rating scale; P-DPN = painful diabetic polyneuropathy; TCNS = } \\
\text { Toronto Clinical Neuropathy Score. } \\
\text { Results are presented as numbers with percentages or medians with interquartile range, except for age, which was normally distributed and is, therefore, } \\
\text { presented as means } \pm \text { SD. } \\
\text { TCNS of }>5 \text { is defined as DPN. } \\
\text { a } p<0.05 \text { between patients with NP-DPN and controls without diabetes. } \\
\text { b } p<0.05 \text { between patients with P-DPN and those with NP-DPN. }\end{array}$} \\
\hline
\end{tabular}


Figure 1 Dot Plot of Macrophage Density, Calcitonin Gene-Related Peptide, and Substance P in Controls, Patients With NPDPN, and Patients With P-DPN

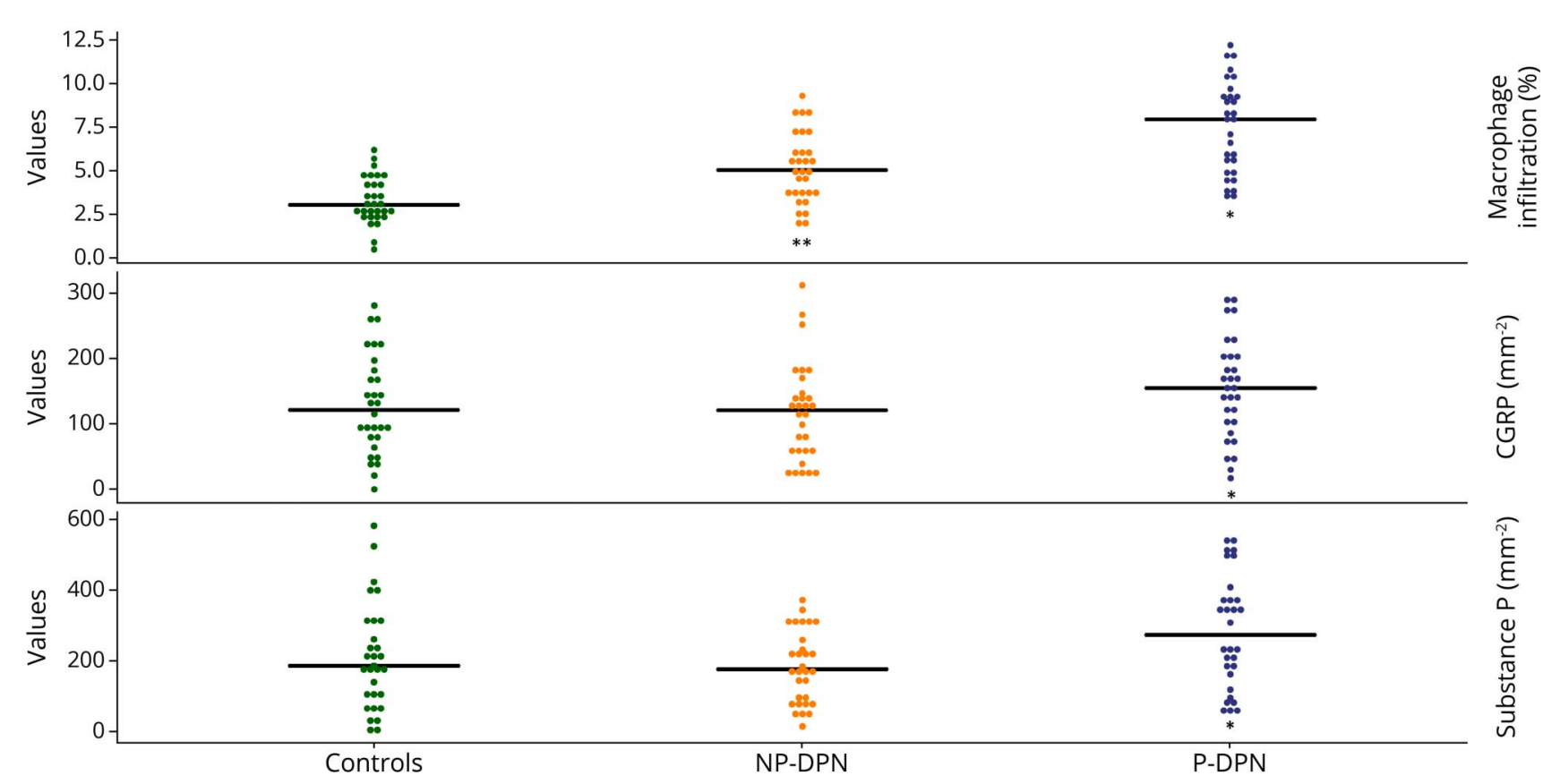

${ }^{*} p<0.05$ between patients with P-DPN and patients with NP-DPN, ${ }^{*}{ }^{*} p<0.05$ between patients with NP-DPN and controls without diabetes. NP-PDN $=$ nonpainful diabetic polyneuropathy; P-DPN = painful diabetic polyneuropathy.

Patients with P-DPN had more SP-positive and CGRPpositive nerve fibers, compared with patients with NP-DPN and controls, but there was no difference between controls and patients with NP-DPN (Table 1 and Figure 1). Examples of confocal images of peptidergic fibers and macrophage density are shown in Figure 2. When stratifying for sex, there was still difference in macrophage density between patients with P-DPN and patients with NP-DPN. There was a statistically significant difference in CGRP-positive and SP-positive nerve fibers when comparing patients with P-DPN and patients with NP-DPN for female patients but not male patients, although male patients showed the same trend (Table 2).

We categorized participants according to the levels of macrophages in the dermis and neuropeptide immunoreactive sensory fibers (combining SP and CGRP) and defined these as being below (low) and above (high) median values (Table 3). Individuals with high macrophages and high neuropeptides (SP or CGRP or both) were most likely to have P-DPN. In groups with "low" macrophages or high macrophages and low neuropeptides, there was a lower proportion with P-DPN.

\section{Correlations With Clinical Symptoms and Signs}

There was no correlation between pain intensity in the past 24 hours and SP $\left(\mathrm{rho}_{\mathrm{s}, 30}=0.017, p=0.93\right)$, CGRP $\left(\mathrm{rho}_{\mathrm{s}, 30}\right.$ $-0.063, p=0.74)$, or macrophage density $\left(\mathrm{rho}_{\mathrm{s}, 30}=0.072, p=\right.$ 0.71 ) in patients with P-DPN. Neither was there a correlation between macrophage density and neuropeptide infiltration and NPSI sum score (data not shown). As reported earlier, patients with P-DPN had more neuropathy severity, measured by the total TCNS, and more macrophage, SP, and CGRP density compared with patients without P-DPN. However, within the group of patients with P-DPN, there was no correlation between neuropathy severity and macrophage $\left(\mathrm{rho}_{\mathrm{s}, 30}=0.07, p=0.72\right)$, SP $\left(\mathrm{rho}_{\mathrm{s}, 30}=-0.04, p=0.80\right)$, or CGRP $\left(\mathrm{rho}_{s, 30}=0.06, p=0.76\right)$ density.

\section{Discussion}

In this study of carefully phenotyped P-DPN and NP-DPN (according to the established clinical criteria), ${ }^{24,25}$ we demonstrated that patients with P-DPN had higher macrophage density in the skin compared with patients with NP-DPN even after adjusting for BMI, neuropathy severity, age, and sex. There was an increasing gradient of macrophages in the skin of controls relative to patients with NP-DPN and then patients with P-DPN. In addition, consistent with our previous findings in diabetic small fiber neuropathy, we found a higher concentration of peptidergic fibers (containing SP or CGRP) in skin biopsies from patients with P-DPN compared with that in skin biopsies from NP-DPN. Taken together, these findings indicate that it is possible to differentiate P-DPN from NP-DPN based on macrophage density, SP, and CGRP immunoreactivity in skin biopsies. Many factors are known to contribute to neuropathic pain in diabetes; for reviews, see $1,7,12,13,37$, including the release of the neuropeptides SP and CGRP from sensory nerve 

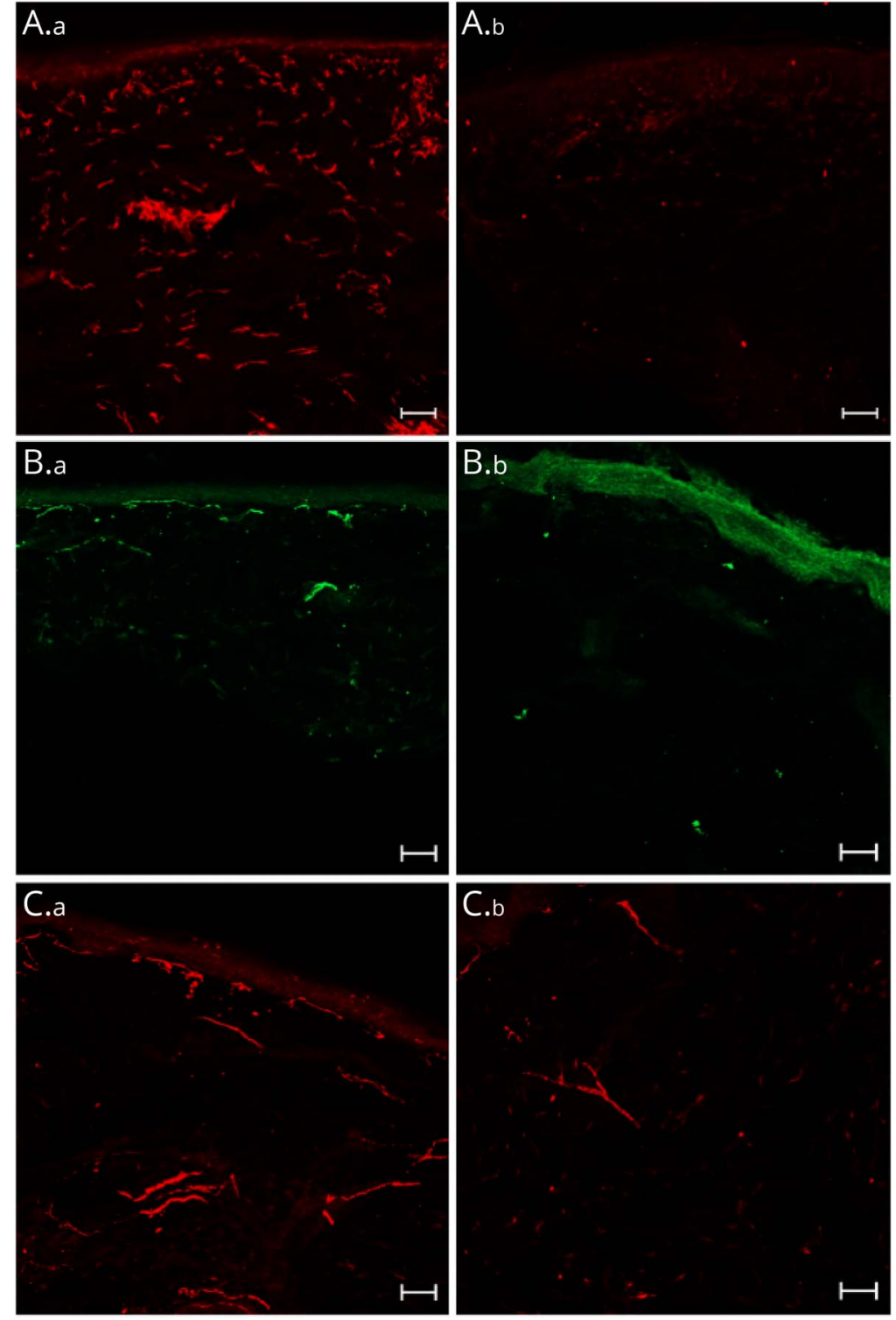

(A) $\mathrm{lbA} 1+$ macrophages (red) in the dermis in a patient with $\mathrm{P}$ DPN (A.a) and in a healthy control (A.b), substance P (green) in the dermis in a patients with P-DPN (B.a) and in a healthy control (B.b), and calcitonin gene-related peptide (red) in the dermis in a patient with P-DPN (C.a) and in a healthy control (C.b). Scale bars: $50 \mu \mathrm{m}$. P-DPN = painful diabetic polyneuropathy. terminals and inflammatory mediators from immune cells. ${ }^{13}$ Sensory neurons in the skin can, through the release of CGRP and SP from their terminals, give rise to neurogenic inflammation with vasodilatation and modulation of the immune system. Conversely, peripheral terminals of nociceptors can be activated by cytokines and chemokines released from immune cells such as resident macrophages (for reviews, see ref. 13,38). A recent study showed that macrophages were required in the angiotensin II induction of mechanical pain hypersensitivity in rodents through the AT2R and TRPV1 channel on sensory nerves. ${ }^{18}$ These findings of increased macrophages and increased CGRPexpressing and SP-expressing nerve fibers in the skin of patients with P-DPN may be consistent with a role of the immune system and neuropeptides in driving pain in DPN. A study on macrophages in the skin of patients with neuropathy of various causes, including DPN, found increased cutaneous inflammatory cells including CD68-positive macrophages in the skin of patients with polyneuropathy. ${ }^{39}$ In this study, we did not specifically measure activated macrophages (for instance, using CD68 immunoreactivity or cytokine expression ${ }^{39}$ ). Although we can comment on macrophage density, we are unable to comment on activation status, and additional studies will be needed to clarify this.

Peptidergic fibers are known to be implicated in nociception and to directly contribute to neuropathic pain conditions. 40,41 In this study, we found morphological evidence of increased peptidergic fibers in patients with P-DPN (although not reaching statistical significance in male patients), further confirming our previous findings in an Italian cohort of 
Table 2 Comparison Between Patients With NP-DPN and Those With P-DPN Stratified by Sex for Macrophages, CGRP, and SP

\begin{tabular}{lllll}
\hline & Controls without diabetes & Patients with NP-DPN & Patients with P-DPN & $\boldsymbol{p}$ Value for NP vs P-DPN \\
\hline Females & $19(63.3 \%)$ & $8(26.7 \%)$ & $15(50 \%)$ & - \\
\hline Macrophage infiltration \% & $3.1(2.5 ; 4.3)$ & $5.0(3.8 ; 6.4)$ & $8.2(5.0 ; 10.3)$ & 0.018 \\
\hline CGRP NFLD, $\mathbf{~ m}^{-2}$ & $98(64 ; 172)$ & $123(59 ; 137)$ & $156(124 ; 227)$ & 0.024 \\
\hline SP NFLD, $\mathbf{m m}^{-\mathbf{2}}$ & $167(98 ; 241)$ & $176(110 ; 197)$ & $309(204 ; 490)$ & 0.033 \\
\hline Males & $11(36.7 \%)$ & $22(73.3 \%)$ & $15(50 \%)$ & - \\
\hline Macrophage infiltration \% & $3.0(2.5 ; 4.7)$ & $5.1(3.6 ; 6.2)$ & $6.6(4.5 ; 9.3)$ & 0.032 \\
\hline CGRP NFLD, $\mathbf{m m}^{-\mathbf{2}}$ & $141(79 ; \mathbf{2 2 1})$ & $115(56 ; 181)$ & $154(48 ; 202)$ & 0.48 \\
\hline SP nerve fiber length density, $\mathbf{~ m m}^{-\mathbf{2}}$ & $218(73 ; \mathbf{4 0 8 )}$ & $193(86 ; 307)$ & $216(95 ; 364)$ & 0.15 \\
\hline
\end{tabular}

Abbreviations: CGRP = calcitonin gene-related peptide; NFLD = nerve fiber length density; NP-DPN = nonpainful diabetic polyneuropathy; P-DPN = painful diabetic polyneuropathy; SP = substance $P$.

Results are presented as numbers with percentages or medians with interquartile range.

patients with diabetic small fiber neuropathy. ${ }^{21}$ However, contradictory to the findings in the Italian cohort study, we did not find a correlation between the peptidergic nerve fiber density and pain intensity. The reason for this is unclear, but the major differences between the studies include different methods when analyzing the peptidergic nerve fiber density (stereological vs nonstereological counting methods) and differences in nerve fiber involvement because the Italian patients predominantly had involvement of small nerve fibers and intact large fibers (whereas most of our population had small and large fiber involvements).

There are some limitations in this study. Patients in this study had only had diabetes for approximately 5 years, and of those

Table 3 Combination of Neuropeptide and Macrophage Density in the Whole Group of 90 Participants (Above and Under Median) and the Subset With P-DPN

\begin{tabular}{llll}
\hline $\begin{array}{l}\text { Neuropeptides } \\
\text { (CGRP or/and SP) }\end{array}$ & Macrophages & $\begin{array}{l}\text { Number } \\
\text { (\%) with } \\
\text { combination (90) }\end{array}$ & $\begin{array}{l}\text { Number (\%) } \\
\text { with combination } \\
\text { having P-DPN (30) }\end{array}$ \\
\hline High & High & $8(8.9)$ & $6(75.0)$ \\
\hline High & High & $7(7.8)$ & $5(71.4)$ \\
\hline High & High & $21(23.3)$ & $12(57.1)$ \\
\hline Low & Low & $23(25.6)$ & $4(17.4)$ \\
\hline High & Low & $6(6.7)$ & $1(16.7)$ \\
\hline Low & High & $9(10.0)$ & $1(11.0)$ \\
\hline High & Low & $11(12.2)$ & $1(9.1)$ \\
\hline
\end{tabular}

Abbreviations: CGRP = calcitonin gene-related peptide; $\mathrm{P}-\mathrm{DPN}=$ painful diabetic polyneuropathy; SP = substance $\mathrm{P}$.

High = above average (median).

Low $=$ under average (median). with painful symptoms, they reported a median pain intensity of 5 on the NRS scale in the past 24 hours, and so, most did not experience severe DPN. ${ }^{22}$ It is possible that with inclusion of more severely affected patients with DPN, more pronounced changes would have been observed. As already mentioned, we did not measure other immune cell parameters such as the activation status of macrophages and blood cytokines. Nor did we include markers of LCs or quantify the total dermal nerve fiber density. During the random selection of 30 patients from each patient group, we did not account for uneven allocation of the sexes, which resulted in uneven distribution of sex in the groups and may, therefore, have influenced the findings, although we did stratify for sex in our analysis.

\section{Study Funding}

Novo Nordisk Foundation Challenge programme grant (Grant number NNF14OC0011633), Novo Nordisk Foundation (Grant number NNF18OC0052301).

\section{Disclosure}

D.L.H. Bennett has acted as a consultant in the last 2 years for Amgen, CODA Therapeutic, LatigoBio, Olipass, Orion, Regeneron, and Theranexus on behalf of Oxford University Innovation. These companies are developing novel therapeutics for the treatment of neuropathic pain. D.L.H. Bennett has acted as a consultant in the last 2 years for Lilly, which manufactures Duloxetine used to treat painful diabetic neuropathy on behalf of Oxford University Innovation. N. Finnerup reports personal fees from Merck, Almirall, Vertex, NeuroPN, and Novartis Pharma, has undertaken consultancy work for Aarhus University with remunerated work for Biogen, Merz, and Confo Therapeutics, and has received a research grant from EU IMI Paincare, an EU IMI 2 (Innovative medicines initiative) public-private consortium, and the companies involved are as follows: Grünenthal, Bayer, Eli Lilly, Esteve, and Teva outside the submitted work. P. Karlsson has received personal fees from Grünenthal and 
Alnylam and has received a research grant from Merck and Ipsen outside the submitted work. J. Nyengaard has received a research grant from Ipsen outside the submitted work. The other authors do not report potential conflicts of interest. Go to Neurology.org/NN for full disclosures.

\section{Publication History}

Received by Neurology: Neuroimmunology \& Neuroinflammation May 4, 2021. Accepted in final form October 4, 2021.

Appendix Authors

\begin{tabular}{lll}
\hline Name & Location & Contribution \\
\hline Sandra Sif & Danish Pain Research Center, & Drafting/revision of the \\
Gylfadottir, & Department of Clinical & article for content, \\
MD, PhD & Medicine, Aarhus University, & including medical writing \\
& Denmark; Department of & for content; major role in \\
& Neurology, Aarhus University & the acquisition of data; \\
& Hospital, Denmark & study concept or design; \\
& & and analysis or \\
& & interpretation of data
\end{tabular}

Mustapha Research Unit for Neurology, Drafting/revision of the Itani, MD Odense University Hospital, article for content, Denmark; University of including medical writing Southern Denmark, Odense, for content; major role in Denmark the acquisition of data; study concept or design; and analysis or interpretation of data

\begin{tabular}{ll}
\hline Alexander & Department of Clinical \\
Gramm & Neurophysiology, Aarhus \\
Kristensen, & University Hospital, Denmark \\
MD &
\end{tabular}

Drafting/revision of the article for content, including medical writing for content; major role in the acquisition of data; study concept or design; and analysis or interpretation of data

\section{\begin{tabular}{lll}
\hline Hatice & Department of Clinical & Drafting/revision of the \\
Tankisi, MD, & Neurophysiology, Aarhus & article for content,
\end{tabular}} Tankisi, MD, Neurophysiology, Aarhus

PhD University Hospital, Denmark
for content; major role in the acquisition of data; study concept or design; and analysis or interpretation of data

\begin{tabular}{lll}
\hline Troels & Danish Pain Research Center, & Drafting/revision of the \\
Staehelin & Department of Clinical & article for content, \\
Jensen, MD, & Medicine, Aarhus University, & including medical writing \\
PhD & Denmark; Department of & for content; major role in \\
& Neurology, Aarhus University & the acquisition of data; \\
& Hospital, Denmark & study concept or design; \\
& and analysis or \\
& interpretation of data
\end{tabular}

\begin{tabular}{lll}
\hline $\begin{array}{l}\text { Søren H. } \\
\text { Sindrup, MD, } \\
\text { PhD }\end{array}$ & $\begin{array}{l}\text { Research Unit for Neurology, } \\
\text { Odense University Hospital, } \\
\text { Denmark; University of } \\
\text { Southern Denmark, Odense, } \\
\text { Denmark }\end{array}$ & $\begin{array}{l}\text { Drafting/revision of the } \\
\text { article for content, } \\
\text { including medical writing } \\
\text { for content; major role in } \\
\text { the acquisition of data; } \\
\text { study concept or design; } \\
\text { and analysis or } \\
\text { interpretation of data }\end{array}$ \\
\hline $\begin{array}{ll}\text { David L.H. } \\
\text { Bennett, MD }\end{array}$ & $\begin{array}{l}\text { Nuffield Department of } \\
\text { Clinical Neurosciences, } \\
\text { University of Oxford, UK }\end{array}$ & $\begin{array}{l}\text { Drafting/revision of the } \\
\text { article for content, } \\
\text { including medical writing } \\
\text { for content; major role in } \\
\text { the acquisition of data; } \\
\text { study concept or design; } \\
\text { and analysis or } \\
\text { interpretation of data }\end{array}$ \\
& &
\end{tabular}

Appendix (continued)

\begin{tabular}{|c|c|c|}
\hline Name & Location & Contribution \\
\hline $\begin{array}{l}\text { Jens Randel } \\
\text { Nyengaard, } \\
\text { MD, PhD }\end{array}$ & $\begin{array}{l}\text { Core Center for Molecular } \\
\text { Morphology, Section for } \\
\text { Stereology and Microscopy, } \\
\text { Department of Clinical } \\
\text { Medicine, Aarhus University, } \\
\text { Denmark; Department of } \\
\text { Pathology, Aarhus University } \\
\text { Hospital, Denmark }\end{array}$ & $\begin{array}{l}\text { Drafting/revision of the } \\
\text { article for content, } \\
\text { including medical writing } \\
\text { for content; major role in } \\
\text { the acquisition of data; } \\
\text { study concept or design; } \\
\text { and analysis or } \\
\text { interpretation of data }\end{array}$ \\
\hline $\begin{array}{l}\text { Nanna Brix } \\
\text { Finnerup, } \\
\text { MD }\end{array}$ & $\begin{array}{l}\text { Danish Pain Research Center, } \\
\text { Department of Clinical } \\
\text { Medicine, Aarhus University, } \\
\text { Denmark; Department of } \\
\text { Neurology, Aarhus University } \\
\text { Hospital, Denmark }\end{array}$ & $\begin{array}{l}\text { Drafting/revision of the } \\
\text { article for content, } \\
\text { including medical writing } \\
\text { for content; major role in } \\
\text { the acquisition of data; } \\
\text { study concept or design; } \\
\text { and analysis or } \\
\text { interpretation of data }\end{array}$ \\
\hline $\begin{array}{l}\text { Pall Karlsson, } \\
\text { PhD }\end{array}$ & $\begin{array}{l}\text { Danish Pain Research Center, } \\
\text { Department of Clinical } \\
\text { Medicine, Aarhus University, } \\
\text { Denmark; Core Center for } \\
\text { Molecular Morphology, } \\
\text { Section for Stereology and } \\
\text { Microscopy, Department of } \\
\text { Clinical Medicine, Aarhus } \\
\text { University, Denmark }\end{array}$ & $\begin{array}{l}\text { Drafting/revision of the } \\
\text { article for content, } \\
\text { including medical writing } \\
\text { for content; major role in } \\
\text { the acquisition of data; } \\
\text { study concept or design; } \\
\text { and analysis or } \\
\text { interpretation of data }\end{array}$ \\
\hline
\end{tabular}

\section{References}

1. Feldman EL, Callaghan BC, Pop-Busui R, et al. Diabetic neuropathy. Nat Rev Dis Primers. 2019;5(1):41.

2. Callaghan BC, Cheng HT, Stables CL, Smith AL, Feldman EL. Diabetic neuropathy: clinical manifestations and current treatments. Lancet Neurol. 2012;11(6):521-534.

3. Abbott CA, Malik RA, van Ross ER, Kulkarni J, Boulton AJ. Prevalence and characteristics of painful diabetic neuropathy in a large community-based diabetic population in the U.K. Diabetes Care. 2011;34(10):2220-2224.

4. Bouhassira D, Letanoux M, Hartemann A. Chronic pain with neuropathic characteristics in diabetic patients: a French cross-sectional study. PLoS One. 2013;8(9): e74195.

5. Gylfadottir SS, Christensen DH, Nicolaisen SK, et al. Diabetic polyneuropathy and pain, prevalence, and patient characteristics: a cross-sectional questionnaire study of 5,514 patients with recently diagnosed type 2 diabetes. Pain. 2020;161(3):574-583.

6. Itani $\mathrm{M}$, Gylfadottir SS, Krøigård $\mathrm{T}$, et al. Small and large fiber sensory polyneuropathy in type 2 diabetes: influence of diagnostic criteria on neuropathy subtypes. J Peripher Nerv Syst. 2021;26(1):55-65.

7. Jensen TS, Karlsson P, Gylfadottir SS, et al. Painful and non-painful diabetic neuropathy, diagnostic challenges and implications for future management. Brain. 2021, 144(6):1632-1645

8. Lauria G, Hsieh ST, Johansson O, et al. European federation of neurological societies/ peripheral nerve society guideline on the use of skin biopsy in the diagnosis of small fiber neuropathy. Report of a joint task force of the European federation of neurological societies and the peripheral nerve society. Eur J Neurol. 2010;17(7):903-912.

9. Karlsson P, Hincker AM, Jensen TS, Freeman R, Haroutounian S. Structural, functional, and symptom relations in painful distal symmetric polyneuropathies: a systematic review. Pain. 2019;160(2):286-297.

10. Petersen KL, Rice FL, Farhadi M, Reda H, Rowbotham MC. Natural history of cutaneous innervation following herpes zoster. Pain. 2010;150(1):75-82.

11. Albrecht PJ, Hines S, Eisenberg E, et al. Pathologic alterations of cutaneous innervation and vasculature in affected limbs from patients with complex regional pain syndrome. Pain. 2006;120(3):244-266.

12. Finnerup NB, Kuner R, Jensen TS. Neuropathic pain: from mechanisms to treatment. Physiol Rev. 2021;101(1):259-301.

13. Calvo M, Dawes JM, Bennett DL. The role of the immune system in the generation of neuropathic pain. Lancet Neurol. 2012;11(7):629-642.

14. Forstenpointner J, Naleschinski D, Wasner G, Hüllemann P, Binder A, Baron R. Sensitized vasoactive $\mathrm{C}$-nociceptors: key fibers in peripheral neuropathic pain. Pain Rep. 2019;4(1):e709.

15. Veiga-Fernandes H, Artis D. Neuronal-immune system cross-talk in homeostasis. Science. 2018;359(6383):1465-1466.

16. Veiga-Fernandes H, Pachnis V. Neuroimmune regulation during intestinal development and homeostasis. Nat Immunol. 2017;18(2):116-122.

17. Veiga-Fernandes H, Mucida D. Neuro-immune interactions at barrier surfaces. Cell. 2016;165(4):801-811. 
18. Shepherd AJ, Copits BA, Mickle AD, et al. Angiotensin II triggers peripheral macrophage-to-sensory neuron redox crosstalk to elicit pain. J Neurosci. 2018;38(32): 7032-7057.

19. Anand P. Neurotrophins and peripheral neuropathy. Philos Trans R Soc Lond B Biol Sci. 1996;351(1338):449-454.

20. Basbaum AI, Bautista DM, Scherrer G, Julius D. Cellular and molecular mechanisms of pain. Cell. 2009;139(2):267-284.

21. Karlsson P, Provitera V, Caporaso G, et al. Increased peptidergic fibers as a potential cutaneous marker of pain in diabetic small fiber neuropathy. Pain. 2021;162(3): 778-786.

22. Gylfadottir SS, Itani M, Krøigård $\mathrm{T}$, et al. Diagnosis and prevalence of diabetic polyneuropathy: a cross-sectional study of Danish patients with type 2 diabetes. Eur J Neurol. 2020;27(12):2575-2585.

23. Tesfaye S, Boulton AJ, Dyck PJ, et al. Diabetic neuropathies: update on definitions, diagnostic criteria, estimation of severity, and treatments. Diabetes Care. 2010;33(10): 2285-2293.

24. Finnerup NB, Haroutounian S, Kamerman P, et al. Neuropathic pain: an updated grading system for research and clinical practice. Pain. 2016;157(8):1599-1606.

25. Bouhassira D, Attal N, Fermanian J, et al. Development and validation of the neuropathic pain symptom inventory. Pain. 2004;108(3):248-257.

26. Bril V, Perkins BA. Validation of the Toronto clinical scoring system for diabetic polyneuropathy. Diabetes Care. 2002;25(11):2048-2052.

27. Perkins BA, Olaleye D, Zinman B, Bril V. Simple screening tests for peripheral neuropathy in the diabetes clinic. Diabetes Care. 2001;24(2):250-256.

28. Stålberg E, van Dijk H, Falck B, et al. Standards for quantification of EMG and neurography. Clin Neurophysiol. 2019;130(9):1688-1729.

29. Tankisi H, Pugdahl K, Fuglsang-Frederiksen A, et al. Pathophysiology inferred from electrodiagnostic nerve tests and classification of polyneuropathies suggested guidelines. Clin Neurophysiol. 2005;116(7):1571-1580.
30. Dyck PJ, Albers JW, Andersen H, et al. Diabetic polyneuropathies: update on research definition, diagnostic criteria and estimation of severity. Diabetes Metab Res Rev. 2011; 27(7):620-628.

31. Karlsson P, Møller AT, Jensen TS, Nyengaard JR. Epidermal nerve fiber length density estimation using global spatial sampling in healthy subjects and neuropathy patients. J Neuropathol Exp Neurol. 2013;72(3):186-193.

32. Karlsson P, Porretta-Serapiglia C, Lombardi R, Jensen TS, Lauria G. Dermal innervation in healthy subjects and small fiber neuropathy patients: a stereological reappraisal. J Peripher Nerv Syst. 2013;18(1):48-53.

33. Buch NS, Nikolajsen L, Karlsson P. Possible inflammatory pain biomarkers in postamputation pain. Scand J Pain. 2019;19(3):623-627.

34. Fernandez M, Boudreaux BB, Wilson L, Moore PF, Rademacher N, Pucheu-Haston C. Invasive histiocytoma in the ear canal of a dog. Vet Dermatol. 2020;31(4):317-e80.

35. West HC, Bennett CL. Redefining the role of Langerhans cells as immune regulators within the skin. Front Immunol. 2018;8:1941.

36. Team RCR. A Language and Environment for Statistical Computing: R Foundation for Statistical Computing; 2019.

37. Feldman EL, Nave KA, Jensen TS, Bennett DLH. New horizons in diabetic neuropathy: mechanisms, bioenergetics, and pain. Neuron. 2017;93(6):1296-1313.

38. McMahon SB, La Russa F, Bennett DL. Crosstalk between the nociceptive and immune systems in host defence and disease. Nat Rev Neurosci. 2015;16(7): 389-402.

39. Üçeyler N, Braunsdorf S, Kunze E, et al. Cellular infiltrates in skin and sural nerve of patients with polyneuropathies. Muscle Nerve. 2017;55(6):884-893.

40. Finnerup NB. Nonnarcotic methods of pain management. N Engl J Med. 2019; 380(25):2440-2448.

41. Dussor G, Koerber HR, Oaklander AL, Rice FL, Molliver DC. Nucleotide signaling and cutaneous mechanisms of pain transduction. Brain Res Rev. 2009; $60(1): 24-35$. 


\title{
Neurology \\ Neuroimmunology \& Neuroinflammation
}

\author{
Analysis of Macrophages and Peptidergic Fibers in the Skin of Patients With Painful \\ Diabetic Polyneuropathy \\ Sandra Sif Gylfadottir, Mustapha Itani, Alexander Gramm Kristensen, et al. \\ Neurol Neuroimmunol Neuroinflamm 2022;9; \\ DOI 10.1212/NXI.0000000000001111
}

This information is current as of November 11, 2021

Updated Information \&
Services
References
Subspecialty Collections

Errata

Permissions \& Licensing

Reprints including high resolution figures, can be found at:

http://nn.neurology.org/content/9/1/e1111.full.html

This article cites 40 articles, 6 of which you can access for free at: http://nn.neurology.org/content/9/1/e1111.full.html\#\#ref-list-1

This article, along with others on similar topics, appears in the following collection(s):

Neuropathic pain

http://nn.neurology.org//cgi/collection/neuropathic_pain

Peripheral neuropathy

http://nn.neurology.org//cgi/collection/peripheral_neuropathy

An erratum has been published regarding this article. Please see next page or:

/content/9/6/e200054.full.pdf

Information about reproducing this article in parts (figures,tables) or in its entirety can be found online at:

http://nn.neurology.org/misc/about.xhtml\#permissions

Information about ordering reprints can be found online:

http://nn.neurology.org/misc/addir.xhtml\#reprintsus

Neurol Neuroimmunol Neuroinflamm is an official journal of the American Academy of Neurology.

Published since April 2014, it is an open-access, online-only, continuous publication journal. Copyright

Copyright $@ 2021$ The Author(s). Published by Wolters Kluwer Health, Inc. on behalf of the American

Academy of Neurology.. All rights reserved. Online ISSN: 2332-7812.

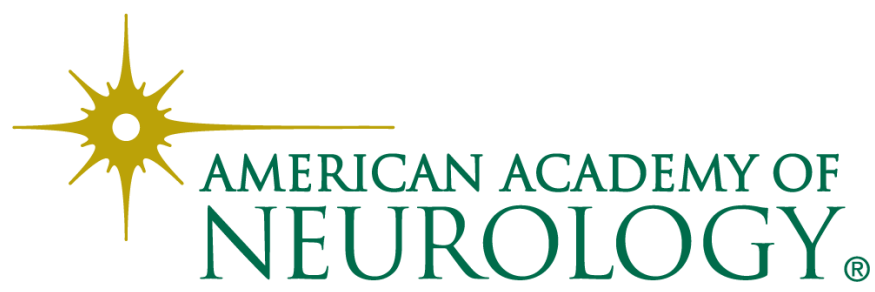




\section{Analysis of Macrophages and Peptidergic Fibers in the Skin of Patients With Painful Diabetic Polyneuropathy}

Neurol Neuroimmunol Neuroinflamm 2022;9:e200054. doi:10.1212/NXI.0000000000200054

In the Article "Analysis of Macrophages and Peptidergic Fibers in the Skin of Patients With Painful Diabetic Polyneuropathy" by Gylfadottir et al. ${ }^{1}$, the seventh author's name should be listed as "David L.H. Bennett." The article has been replaced by a corrected version. The authors regret the error.

\section{Reference}

1. Gylfadottir SS, Itani M, Kristensen AG, et al. Analysis of macrophages and peptidergic fibers in the skin of patients with painful diabetic polyneuropathy. Neurol Neuroimmunol Neuroinflamm. 2022;9(1):e1111. 